\title{
Bending Properties of Fiber-Reinforced Composites Retainers Bonded with Spot-Composite Coverage
}

\author{
Maria Francesca Sfondrini, ${ }^{1}$ Paola Gandini, ${ }^{1}$ Paola Tessera, ${ }^{1}$ Pekka K. Vallittu, ${ }^{2,3}$ \\ Lippo Lassila, ${ }^{2}$ and Andrea Scribante ${ }^{1}$ \\ ${ }^{1}$ Unit of Orthodontics and Paediatric Dentistry, Section of Dentistry, Department of Clinical, Surgical, \\ Diagnostic and Paediatric Sciences, University of Pavia, Pavia, Italy \\ ${ }^{2}$ Department of Biomaterial Science and Turku Clinical Biomaterials Centre (TCBC), Institute of Dentistry, \\ University of Turku, Turku, Finland \\ ${ }^{3}$ City of Turku, Welfare Division, Turku, Finland \\ Correspondence should be addressed to Andrea Scribante; andrea.scribante@unipv.it
}

Received 1 June 2017; Revised 27 August 2017; Accepted 6 September 2017; Published 10 October 2017

Academic Editor: Nick Silikas

Copyright (C) 2017 Maria Francesca Sfondrini et al. This is an open access article distributed under the Creative Commons Attribution License, which permits unrestricted use, distribution, and reproduction in any medium, provided the original work is properly cited.

\begin{abstract}
Orthodontic and periodontal splints are prepared with round or flat metallic wires. As these devices cannot be used in patients with allergy to metals or with aesthetic demands, fiber-reinforced composite (FRC) retainers have been introduced. Stiffness of FRC materials could reduce physiologic tooth movement. In order to lower rigidity of conventional FRC retainers, a modified construction technique that provided a partial (spot) composite coverage of the fiber has been tested and compared with metallic splints and full-bonded FRCs. Flat (Bond-a-Braid, Reliance Orthodontic Products) and round (Penta-one 0155, Masel Orthodontics) stainless steel splints, conventional FRC splints, and experimental spot-bonded FRC retainers (Everstick Ortho, StickTech) were investigated. The strength to bend the retainers at $0.1 \mathrm{~mm}$ deflection and at maximum load was measured with a modified Frasaco model. No significant differences were reported among load values of stainless steel wires and experimental spotbonded FRC retainers at $0.1 \mathrm{~mm}$ deflection. Higher strength values were recoded for conventional full-bonded FRCs. At maximum load no significant differences were reported between metallic splints (flat and round) and experimental spot-bonded FRCs, and no significant differences were reported between spot- and full-bonded FRC splints. These results encourage further tests in order to evaluate clinical applications of experimental spot-bonded FRC retainers.
\end{abstract}

\section{Introduction}

The retention of teeth in the upper and lower jaw is often required after orthodontic treatment or for periodontal reasons [1]. Usually the stabilization is obtained with flat or round multistranded metallic wires. Splints have been introduced initially as canine-to-canine metallic round retainers [2]. Subsequently, in order to prevent incisors undesirable movements, round and then flat splints bonded to all anterior teeth were introduced [3]. Numerous types of fixed retainers have been described in literature with many sizes, diameters, and shapes [4]. These devices are very common but they cannot be used in patients that have to undergo nuclear magnetic resonance, as during the exam the metal could raise in temperature or interfere with image quality [5]. Moreover, also hypersensitivity to nickel and other metals may cause type IV allergic reactions, thus preventing the use of multistranded splints [6]. Finally, in patients with high aesthetic demands, the presence of metallic structures, even if almost or totally invisible, could slightly lower tooth translucency [7]. On the basis of these concerns, fiber-reinforced composites (FRC) retainers have been introduced for multiple clinical applications [8,9]. In fact the reinforcement of composite with short or long fibers (Carbon, Aramid, Polyethylene, Glass) provide better mechanical and physical properties over unreinforced materials $[10,11]$. FRC splints are metal-free and provide excellent aesthetical results [12]. 
TABLE 1: Materials tested.

\begin{tabular}{lcccc}
\hline Denomination & Flat metallic wire & Round metallic wire & Fiber reinforced composite & Fiber reinforced composite \\
\hline Code & FW & RW & SF & FF \\
Manufacturer & Reliance & Masel & StickTech & StickTech \\
Name & Bond-a-Braid & Penta-one 0155 & FRC Ortho & FRC Ortho \\
Design & Ribbon arch & Coaxial & Unidirectional fiber bundle & Unidirectional fiber bundle \\
Material & Stainless steel & Stainless steel & E-glass fiber $15 \mu \mathrm{m}$ & E-glass fiber $15 \mu \mathrm{m}$ \\
Dimensions & $0.673 \mathrm{~mm} \times 0.268 \mathrm{~mm}$ & Diameter: $0.394 \mathrm{~mm}$ & Diameter: $0.75 \mathrm{~mm}$ & Diameter: $0.75 \mathrm{~mm}$ \\
Unit amount & 8 wires & 5 wires & 1000 fibers & 1000 fibers \\
Bonding technique & Conventional spot & Conventional spot & Experimental spot & Conventional full \\
\hline
\end{tabular}

Clinical reliability of FRC retainers has been tested, showing conflicting results. Some reports reported similar [13-15] or higher [16] efficiency if compared with metallic splints. On the other hand some authors [1] reported less reliability if compared to conventional retainers over time. The variability of the results can be related to different fibers and techniques tested in the various investigations. Therefore it is still unclear if FRCs behavior allows better performances over metallic splints. However FRC retainers are nowadays widely used in clinical dentistry [15].

Moreover these materials showed significantly higher stiffness than conventional metallic splints and wires [17-20]. This characteristic could reduce physiologic tooth movement and this could lead to a higher ankylosis risk for the teeth involved [21].

FRC rigidity is mainly related to composite bulk that covers the entire structure once the fiber is placed onto teeth surfaces [22]. The total composite coverage of FRCs is suggested from the manufacturer $[12,13]$. In fact, an experimental preparation technique that would involve composite coverage of FRCs only in correspondence of the teeth would leave the fiber exposed in the interproximal zones, thus mimicking conventional metallic splint rigidity and mechanical behavior.

To our knowledge in literature FRCs have been tested only with a full composite coverage technique, whereas no studies evaluated mechanical properties of FRC splints prepared with a spot-bonded technique. Therefore the purpose of the present report was to evaluate the load to bend FRC splints prepared with both full- and spot-bonding techniques and to compare FRCs with conventional metallic flat or round splints. The null hypothesis of the present report was that there are no significant differences among the various groups tested.

\section{Materials and Methods}

In the present investigation, rectangular metallic splints (Bond-a-Braid, Reliance Orthodontic Products, Bond-aBraid, Reliance Orthodontic Products Inc., Itasca, IL, USA), round metallic splints (Penta-one 0155, Masel Orthodontics, Carlsbad, CA, USA), and FRCs (Everstick Ortho, StickTech, Turku, Finland) were tested (Table 1).
All materials were divided into coded groups of $10 \mathrm{spec}-$ imen each (length: $28 \mathrm{~mm}$ ), according to different bonding techniques:

(i) FW: flat metallic wire;

(ii) RW: round metallic wire;

(iii) FS: FRC spot-bonded;

(iv) FF: FRC full-bonded.

All specimens were then prepared to be bonded to an acrylic Frasaco mandible model, simulating a canine-to-canine splint [23]. Element 3.1 was inserted to the correspondent hole without rigid fixation, thus allowing vertical movement of the tooth. On the other hand, other acrylic teeth were screwed to their correspondent holes. The metallic and FRC splints were bonded to each element from 3.3 to 4.3 with a one-step, self-etch 7 th generation bonding agent (G-aenial Bond, GC America, Alsip, IL, USA) and fixed with flow composite (G-aenial Universal Flo, GC America, Alsip, IL, USA). As showed in Figure 1, the composite covered the retainer only in correspondence of each tooth, thus leaving the splint exposed in interproximal zones (Codes FW, RW, and FS). Conversely, composite coverage was performed also in interproximal spaces in full-bonded FRC splints (code: FF). All specimens were then light cured with ahalogen lamp (Elipar S10, 3M, Monrovia, CA, USA) with a light intensity of $1200 \mathrm{~mW} / \mathrm{cm}^{2}$ and a wavelength range of $430-480 \mathrm{~nm}$ for 40 seconds for each tooth.

Subsequently the strength to bend the retainer in correspondence of element 3.1 was measured at $0.1 \mathrm{~mm}$ deflection (groups 1 to 4 ) and at maximum load (groups 5 to 8 ) with a universal testing machine (Lloyd LRX; Lloyd Instruments, Fareham, United Kingdom). The crosshead speed was set at $1.0 \mathrm{~mm}$ per minute $[18,19]$. The strength values were recorded in newton with Nexygen MT software (Lloyd Instruments).

Data were submitted to statistical analysis using computer software ( $\mathrm{R}$ version 3.1.3, R Development Core Team, R Foundation for Statistical Computing, Wien, Austria). Descriptive statistics including mean, standard deviation, minimum, median, and maximum were calculated for the 8 groups. The normality of the data was calculated using the KolmogorovSmirnov test and confirmed with graphs in order to avoid 


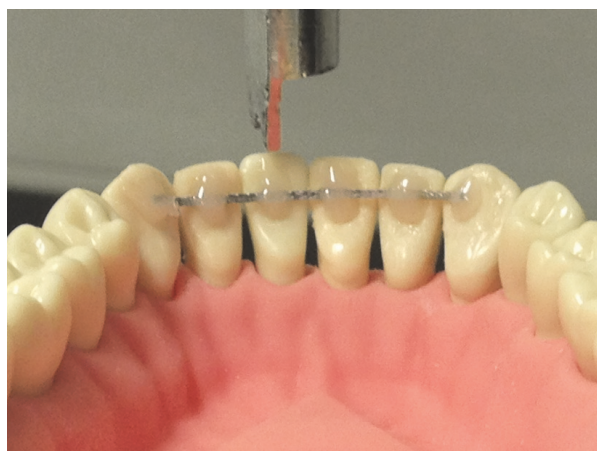

(a)

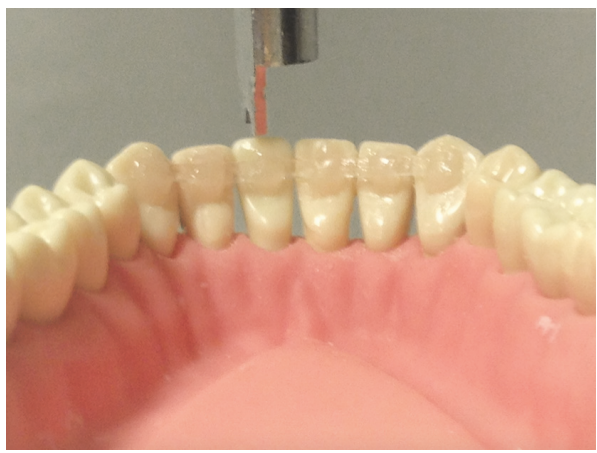

(c)

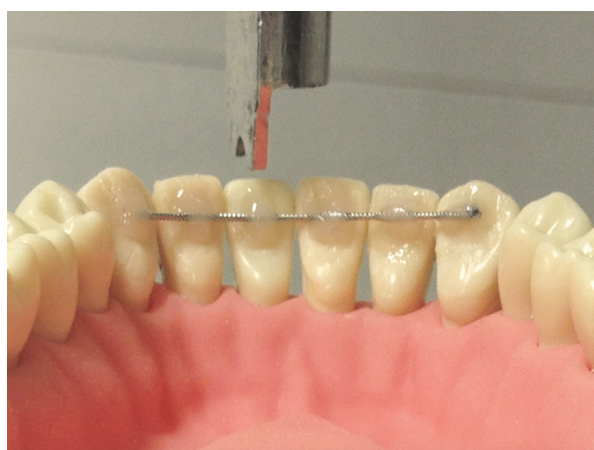

(b)

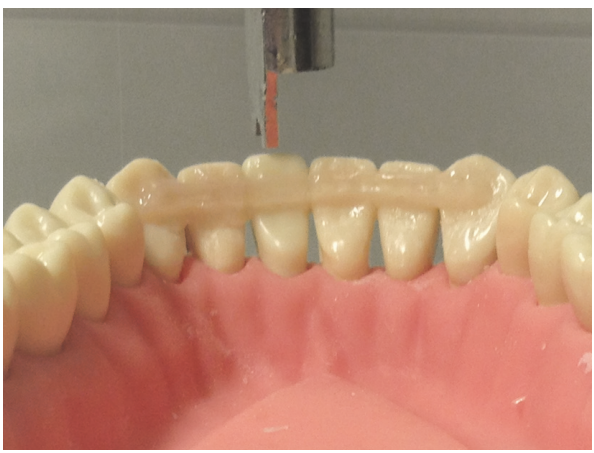

(d)

FIGURE 1: Flat metallic splint (a) round metallic splint (b) experimental spot-bonded FRC (c) and conventional full-bonded FRC (d).

TABLE 2: Descriptive statistics $(N)$ of load values of the 8 groups tested (each group consisted of 10 specimens).

\begin{tabular}{|c|c|c|c|c|c|c|c|c|c|c|c|}
\hline Group & Code & Material & Shape & Bonding & Deflection & Mean & $\mathrm{SD}$ & Min & Mdn & Max & Post hoc \\
\hline 1 & FW & Stainless steel & Flat wire & Spot bonded & $0.1 \mathrm{~mm}$ & 8.33 & 1.68 & 6.19 & 8.90 & 10.76 & A \\
\hline 2 & RW & Stainless steel & Round wire & Spot bonded & $0.1 \mathrm{~mm}$ & 4.24 & 1.16 & 3.23 & 3.84 & 6.66 & A \\
\hline 3 & FS & FRC & Fiber bundle & Spot bonded & $0.1 \mathrm{~mm}$ & 16.67 & 2.08 & 13.53 & 16.18 & 19.33 & A \\
\hline 4 & $\mathrm{FF}$ & FRC & Fiber bundle & Full bonded & $0.1 \mathrm{~mm}$ & 41.73 & 16.16 & 12.18 & 44.52 & 58.64 & B, C, D \\
\hline 5 & FW & Stainless steel & Flat wire & Spot bonded & max load & 34.96 & 6.76 & 22.86 & 35.79 & 44.86 & B \\
\hline 6 & RW & Stainless steel & Round wire & Spot bonded & max load & 35.62 & 10.26 & 21.22 & 38.19 & 50.74 & B \\
\hline 7 & FS & FRC & Fiber bundle & Spot bonded & $\max$ load & 41.44 & 9.19 & 29.31 & 40.32 & 53.46 & $\mathrm{~B}, \mathrm{D}$ \\
\hline 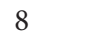 & FF & FRC & Fiber bundle & Full bonded & max load & 52.93 & 18.84 & 15.24 & 57.88 & 74.12 & C, D \\
\hline
\end{tabular}

Mean with same letters is not significantly different.

misunderstanding due to sample size. An analysis of variance (ANOVA) was used and the repeated measures option was set to adjust for the fact that each specimen gave two outcomes. Tukey test was then applied to evaluate differences among the deflection values of the various groups. Statistical results were adjusted for multiple comparisons. Significance for all statistical tests was predetermined at $P<0.05$.

\section{Results}

The descriptive statistics (mean, standard deviation, median, minimum, and maximum) of loads $(N)$ recorded in the 8 groups are showed in Table 2 .
The results of ANOVA indicated the presence of significant differences among the various groups $(P<0.001)$.

Post hoc test pointed out that, at $0.1 \mathrm{~mm}$ (Figure 2, groups 1 to 4 ) deflection, the lowest flexural strengths were recorded for stainless steel flat (group 1) and round (group 2) wires and for spot-bonded FRC (group 3) retainers that showed no significant differences among them $(P<0.05)$. Significantly higher force levels $(P<0.001)$ were reported for full-bonded FRC splints (group 4).

On the other hand, at maximum load (Figure 3, groups 5 to 8$)$ no significant differences $(P>0.05)$ were reported among metallic flat, metallic round, and spot-bonded FRC splints (groups 5, 6, and 7). The highest load values were 


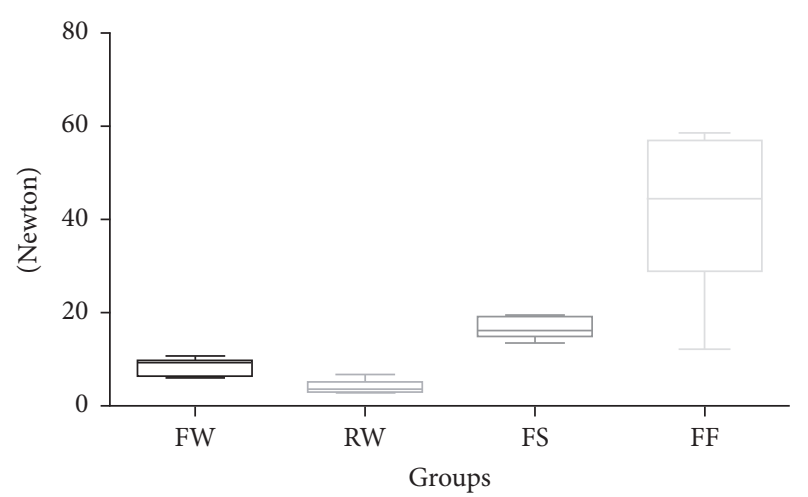

FIGURE 2: Box plot of strength values $(N)$ of the various groups tested at $0.1 \mathrm{~mm}$ deflection.

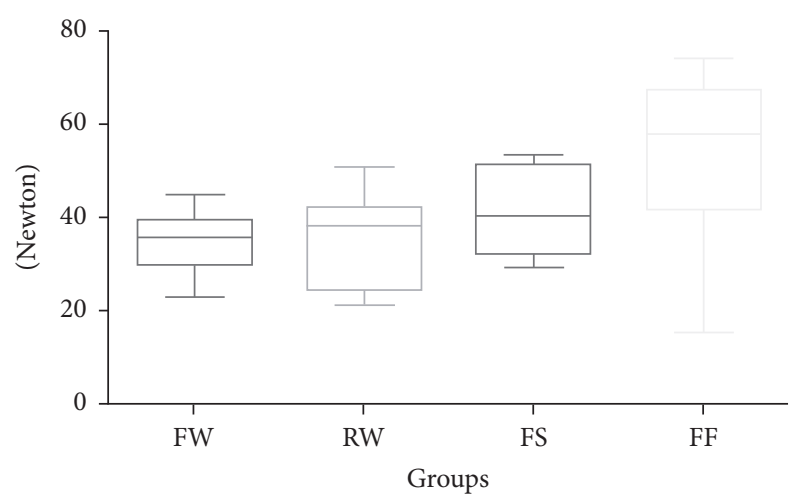

Figure 3: Box plot of strength values $(N)$ of the various groups tested at maximum load.

reported for full-bonded FRC retainers (group 4) that showed no significant differences with spot-bonded FRC splints $(P>$ $0.05)$.

\section{Discussion}

The null hypothesis of the present investigation has been rejected. No significant differences were reported among load values of flat and round stainless steel wires and experimental spot-bonded FRC retainers at $0.1 \mathrm{~mm}$ deflection. Significantly higher strength values were recoded for conventional fullbonded FRCs.

At maximum load no significant differences were reported between metallic splints (flat and round) and experimental spot-bonded FRC retainers. Highest strength values were reported with conventional spot-bonded FRCs; no significant differences were reported between spot- and full-bonded FRC splints.

The high bend values of conventional full-bonded FRCs reported in the present investigation is a confirmation of previous reports that showed high rigidity of FRC splints if compared with metallic splints $[19,20]$ and wires $[17,18]$. Even if it is still controversial if the presence of an excessively rigid bonded lingual retainer has a negative effect on the periodontal tissues, ideal retention would allow physiologic tooth micromovements [21]. In fact, clinicians need to splint groups of teeth for many reasons. First of all, after orthodontic treatment the stability is considered one important goal, as the tendency of relapse has been extensively reported, mostly for lower anterior teeth [24]. Moreover, another reason for splinting is related to periodontal problems, as the teeth that have lost part of their supporting bone can be efficiently stabilized with the aid of provisional or definitive retainers connecting them in groups [16]. Finally, splints are widely used after occasional traumas, to stabilize injured teeth [25].

Multistranded wires have been showed to be a successful retention method for over 40 years [2]. They are well accepted from patients and relatively independent of patient cooperation [4], even if a certain number of patients cannot wear these devices. In fact, the release of nickel, chromium, and other metals from brackets, bars, and splints has been demonstrated [26-29]. Moreover, nuclear magnetic resonance exams require the removal of metal appliances in order to avoid heating and image artifacts risks [5]. For these reasons, FRC splints have been introduced. These retainers made of glass fibers nowadays represent the only esthetic and metal-free material, which can be processed in mouth to the desired shape and subsequently can be directly bonded to teeth surfaces [30]. The bonding technique is easy and fast, no laboratory work is needed, and procedures can be completed in a single appointment $[13,14,18]$.

FRCs are constituted with continuous unidirectional glass (bundle) fibers in dimethacrylate-polymethylmethacrylate resin matrix as a substructure [30]. The FRCs used for retainer preparation are plain fibers and in prepreg form, so that the fibers were preimpregnated with polymethylmethacrylate from the manufacturer [31].

FRC retainers have been tested in literature and their biomechanical behavior is well known. Previous reports that evaluated FRCs flexural strength reported high load values already at minimum deflections $[18,19]$. This is confirmed in the present study for conventional full-bonded FRCs. When comparing the results obtained at $0.1 \mathrm{~mm}$ deflection and at maximum load, a significant increase in strength values was reported for flat and round metallic wires and for spotbonded FRCs. On the other hand, no significant differences were reported for conventional full-bonded FRCs. Therefore, conventional full-bonded FRCs expressed their high rigidity already with minimum deflections, whereas spot-bonded FRCs (as metallic flat and round splints) exhibited high load values only at maximum load. This could be considered an encouraging result improving FRC splints, thus allowing a behavior more similar to metallic retainers than to conventional full-bonded FRC retainers. No other studies to our knowledge evaluated bend values of spot-bonded FRCs.

Other authors evaluated the fatigue of metallic structures and FRCs. Retentive properties of cast metal clasps decrease over time because of metal fatigue. On the other hand, FRC materials showed increased fatigue resistance if compared with metals and may offer a solution to the problem of metal fatigue [31].

Moreover also shear bond strength has been measured both for FRC bundles [32] and nets [33] showing acceptable results. Most common failures in FRC reported in literature 
include intralaminar matrix cracking, longitudinal matrix splitting, fiber/matrix debonding, fiber pull-out, and fiber fracture, which can be often repaired in patients' mouth [30].

Finally clinical reliability of FRC splints has been reported showing many clinical applications $[9,34]$ and acceptable failure rates if compared with conventional multistranded metallic wires [13-15]. On the other hand FRC splints present some disadvantages, as higher costs [18], the difficulty to repair if debonded [13], and high rigidity [17]. In fact, when splinting group of teeth excessive rigidity is unwanted from the clinicians as the reduction of physiologic tooth movement could increase ankyloses risk. The low bend values recorded in the present report for experimental spot-bonded technique are promising in reducing FRCs stiffness.

In fact, the conventional FRC construction technique includes enamel etching, washing, and drying. Subsequently a thin layer of adhesive is applied and light cured, and the FRC is placed on teeth surfaces. Finally the a small account of composite paste or flow is used to cover the entire splint and light cured for 40 seconds for each teeth, as suggested from the manufacturer [12-14]. The experimental FRC preparation technique proposed in the present investigation is quite similar. The main difference is that, after FRC positioning, the composite paste or flow that covers the structure has been placed only in correspondence of each tooth, leaving the FRC free of coverage in interproximal spaces. When composites are cured in air, as in clinical practice, an oxygen inhibition layer $(0.1 \mathrm{~mm}$ thick approximately) is formed on the surface of the freshly cured composite resin. The components of the oxygen inhibition layer present similar composition to those of the uncured resin with reduced amount of photoinitiator [35]. Therefore, also FRCs are affected by this layer, thus reducing their effective diameter of $0.1 \mathrm{~mm}$ approximately [36]. The reduction in diameter has been demonstrated to reduce flexural strength of both conventional $[17,18,37]$ and nanofilled $[38,39]$. This could explain lower bend values showed for experimental spot-bonded FRC in the present investigation. However, in literature no other reports tested spot-bonding technique for FRC retainers. Therefore, further investigation about mechanical characteristics, physical properties, and biocompatibility concerns of these partially uncovered retainers should be conducted before suggesting routinely clinical use.

\section{Conclusions}

The present study demonstrated that experimental spotbonded FRC showed lower load to bend the retainer at $0.1 \mathrm{~mm}$ deflection if compared with conventional full-bonded FRC. Moreover no significant differences were reported among stainless steel flat and round wires and spot-bonded FRCs.

At maximum load no significant differences were reported between metallic splints (flat and round) and experimental spot-bonded FRC retainers, and no significant differences were reported between spot- and full-bonded FRC splints.
The results of the present report encourage further in vitro and in vivo tests in order to evaluate future clinical applications of experimental spot-bonded FRC retainers.

\section{Conflicts of Interest}

The authors declare that there are no conflicts of interest regarding the publication of this paper.

\section{Acknowledgments}

The authors acknowledge GC America, Masel Orthodontics, Reliance Orthodontic Products, and StickTech-GC Group for providing the materials tested in the present study.

\section{References}

[1] M. P. E. Tacken, J. Cosyn, P. De Wilde, J. Aerts, E. Govaerts, and B. V. Vannet, "Glass fibre reinforced versus multistranded bonded orthodontic retainers: a 2 year prospective multi-centre study," European Journal of Orthodontics, vol. 32, no. 2, pp. 117$123,2010$.

[2] E. Gazit and M. A. Lieberman, "An esthetic and effective retainer for lower anterior teeth," American Journal of Orthodontics, vol. 70, no. 1, pp. 91-93, 1976.

[3] B. U. Zachrisson, "The bonded lingual retainers and multiples spacing of anterior teeth," Swedish Dental Journal Supplement, vol. 15, pp. 247-255, 1982.

[4] A. Geramy, J. M. Retrouvey, F. Sobuti, and H. Salehi, "Anterior teeth splinting after orthodontic treatment: 3D analysis using finite element method," Journal of Dentistry, vol. 9, no. 2, pp. 90-98, 2012.

[5] A. Klocke, B. Kahl-Nieke, G. Adam, and J. Kemper, "Magnetic forces on orthodontic wires in high field magnetic resonance imaging (MRI) at 3 Tesla," Journal of Orofacial Orthopedics, vol. 67, no. 6, pp. 424-429, 2006.

[6] H. M. Kerosuo and J. E. Dahl, "Adverse patient reactions during orthodontic treatment with fixed appliances," American Journal of Orthodontics and Dentofacial Orthopedics, vol. 132, no. 6, pp. 789-795, 2007.

[7] H. E. Strassler and C. L. Serio, "Esthetic considerations when splinting with fiber-reinforced composites," Dental Clinics of North America, vol. 51, no. 2, pp. 507-524, 2007.

[8] P. K. Vallittu and V. P. Lassila, "Reinforcement of acrylic resin denture base material with metal or fibre strengtheners," Journal of Oral Rehabilitation, vol. 19, no. 3, pp. 225-230, 1992.

[9] A. I. Karaman, N. Kir, and S. Belli, "Four applications of reinforced polyethylene fiber material in orthodontic practice," American Journal of Orthodontics and Dentofacial Orthopedics, vol. 121, no. 6, pp. 650-654, 2002.

[10] E. G. Başaran, E. Ayna, P. K. Vallittu, and L. V. J. Lassila, "Load bearing capacity of fiber-reinforced and unreinforced composite resin CAD/CAM-fabricated fixed dental prostheses," Journal of Prosthetic Dentistry, vol. 109, no. 2, pp. 88-94, 2013.

[11] J. Bijelic-Donova, S. Garoushi, L. V. J. Lassila, F. Keulemans, and P. K. Vallittu, "Mechanical and structural characterization of discontinuous fiber-reinforced dental resin composite," Journal of Dentistry, vol. 52, pp. 70-78, 2016.

[12] M. A. Freilich, A. C. Karmaker, C. J. Burstone, and A. Goldberg, "Development and clinical applications of a light-polymerized 
fiber-reinforced composite," The Journal of Prosthetic Dentistry, vol. 80, no. 3, pp. 311-318, 1998.

[13] A. Scribante, M. F. Sfondrini, S. Broggini, M. D'Allocco, and P. Gandini, "Efficacy of esthetic retainers: clinical comparison between multistranded wires and direct-bond glass fiberreinforced composite splints," International Journal of Dentistry, vol. 2011, Article ID 548356, 5 pages, 2011.

[14] M.-F. Sfondrini, D. Fraticelli, L. Castellazzi, A. Scribante, and P. Gandini, "Clinical evaluation of bond failures and survival between mandibular canine-to-canine retainers made of flexible spiral wire and fiber-reinforced composite," Journal of Clinical and Experimental Dentistry, vol. 6, no. 2, pp. e145-e149, 2014.

[15] F. Sobouti, V. Rakhshan, M. G. Saravi, A. Zamanian, and M. Shariati, "Two-year survival analysis of twisted wire fixed retainer versus spiral wire and fiber-reinforced composite retainers: A preliminary explorative single-blind randomized clinical trial," Korean Journal of Orthodontics, vol. 46, no. 2, pp. 104-110, 2016.

[16] L. Chandra Sekhar, V. P. Koganti, B. Ravi Shankar, and A. Gopinath, "A comparative study of temporary splints: Bonded polyethylene fiber reinforcement ribbon and stainless steel wire + composite resin splint in the treatment of chronic periodontitis," Journal of Contemporary Dental Practice, vol. 12, no. 5, pp. 343-349, 2011.

[17] V. Cacciafesta, M. F. Sfondrini, A. Lena, A. Scribante, P. K. Vallittu, and L. V. Lassila, "Flexural strengths of fiber-reinforced composites polymerized with conventional light-curing and additional postcuring," American Journal of Orthodontics and Dentofacial Orthopedics, vol. 132, no. 4, pp. 524-527, 2007.

[18] V. Cacciafesta, M. F. Sfondrini, A. Lena, A. Scribante, P. K. Vallittu, and L. V. Lassila, "Force levels of fiber-reinforced composites and orthodontic stainless steel wires: a 3-point bending test," American Journal of Orthodontics and Dentofacial Orthopedics, vol. 133, no. 3, pp. 410-413, 2008.

[19] S. Alavi and T. Mamavi, "Evaluation of load-deflection properties of fiber-reinforced composites and its comparison with stainless steel wires," Dental Research Journal, vol. 11, no. 2, pp. 234-239, 2014.

[20] O. Annousaki, S. Zinelis, G. Eliades, and T. Eliades, "Comparative analysis of the mechanical properties of fiber and stainless steel multistranded wires used for lingual fixed retention," Dental Materials, vol. 33, no. 5, pp. e205-e211, 2017.

[21] M. Oshagh, S. Heidary, A. Dehghani Nazhvani, F. Koohpeima, and O. Koohi Hosseinabadi, "Evaluation of histological impacts of three types of orthodontic fixed retainers on periodontium of rabbits," Journal of Dentistry, vol. 15, no. 3, pp. 104-111, 2014.

[22] Y. Zhu, H. Chen, L. Cen, and J. Wang, "Influence of abutment tooth position and adhesive point dimension on the rigidity of a dental trauma wire-composite splint," Dental Traumatology, vol. 32, no. 3, pp. 225-230, 2016.

[23] J. Bijelic, S. Garoushi, P. K. Vallittu, and L. V. J. Lassila, "Fracture load of tooth restored with fiber post and experimental short fiber composite," Open Dentistry Journal, vol. 5, no. 1, pp. 5865, 2011.

[24] R. M. Little, R. A. Riedel, and J. Artun, "An evaluation of changes in mandibular anterior alignment from 10 to 20 years postretention," American Journal of Orthodontics and Dentofacial Orthopedics, vol. 93, no. 5, pp. 423-428, 1988.

[25] S. Lin, O. Emodi, and I. Abu El-Naaj, "Splinting of an injured tooth as part of emergency treatment," Dental Traumatology, vol. 24, no. 3, pp. 370-372, 2008.
[26] S. Torgersen and N. R. Gjerdet, "Metal release from arch bars used in maxillofacial surgery: an in vitro study," Acta Odontologica Scandinavica, vol. 50, no. 2, pp. 83-89, 1992.

[27] M. F. Sfondrini, V. Cacciafesta, E. Maffia et al., "Chromium release from new stainless steel, recycled and nickel-free orthodontic brackets," Angle Orthodontist, vol. 79, no. 2, pp. 361-367, 2009.

[28] M. F. Sfondrini, V. Cacciafesta, E. Maffia et al., "Nickel release from new conventional stainless steel, recycled, and nickel-free orthodontic brackets: an in vitro study," American Journal of Orthodontics and Dentofacial Orthopedics, vol. 137, no. 6, pp. 809-815, 2010.

[29] A. Milheiro, C. Kleverlaan, J. Muris, A. Feilzer, and P. Pallav, "Nickel release from orthodontic retention wires-the action of mechanical loading and $\mathrm{pH}$," Dental Materials, vol. 28, no. 5, pp. 548-553, 2012.

[30] S. Garoushi, L. Lassila, and P. K. Vallittu, "Resin-bonded fiberreinforced composite for direct replacement of missing anterior teeth: a clinical report," International Journal of Dentistry, Article ID 845420, 2011.

[31] K. K. Narva, L. V. J. Lassila, and P. K. Vallittu, "Fatigue resistance and stiffness of glass fiber-reinforced urethane dimethacrylate composite," Journal of Prosthetic Dentistry, vol. 91, no. 2, pp. 158$163,2004$.

[32] A. Scribante, V. Cacciafesta, and M. F. Sfondrini, "Effect of various adhesive systems on the shear bond strength of fiberreinforced composite," American Journal of Orthodontics and Dentofacial Orthopedics, vol. 130, no. 2, pp. 224-227, 2006.

[33] M. F. Sfondrini, V. Cacciafesta, and A. Scribante, "Shear bond strength of fibre-reinforced composite nets using two different adhesive systems," European Journal of Orthodontics, vol. 33, no. 1, pp. 66-70, 2011.

[34] S. Garoushi and P. Vallittu, "Fiber-reinforced composites in fixed partial dentures," Libyan Journal of Medicine, vol. 1, no. 1, pp. 73-82, 2006.

[35] P. K. Vallittu, "Unpolymerized surface layer of autopolymerizing polymethyl methacrylate resin," Journal of Oral Rehabilitation, vol. 26, no. 3, pp. 208-212, 1999.

[36] J. Bijelic-Donova, S. Garoushi, L. V. J. Lassila, and P. K. Vallittu, "Oxygen inhibition layer of composite resins: effects of layer thickness and surface layer treatment on the interlayer bond strength," European Journal of Oral Sciences, vol. 123, no. 1, pp. 53-60, 2015.

[37] P. Alander, L. V. J. Lassila, and P. K. Vallittu, "The span length and cross-sectional design affect values of strength," Dental Materials, vol. 21, no. 4, pp. 347-353, 2005.

[38] A. Scribante, S. Massironi, G. Pieraccini et al., "Effects of nanofillers on mechanical properties of fiber-reinforced composites polymerized with light-curing and additional postcuring," Journal of Applied Biomaterials and Functional Materials, vol. 13, no. 3, pp. e296-e299, 2015.

[39] M. F. Sfondrini, S. Massironi, G. Pieraccini et al., "Flexural strengths of conventional and nanofilled fiber-reinforced composites: a three-point bending test," Dental Traumatology, vol. 30, no. 1, pp. 32-35, 2014. 

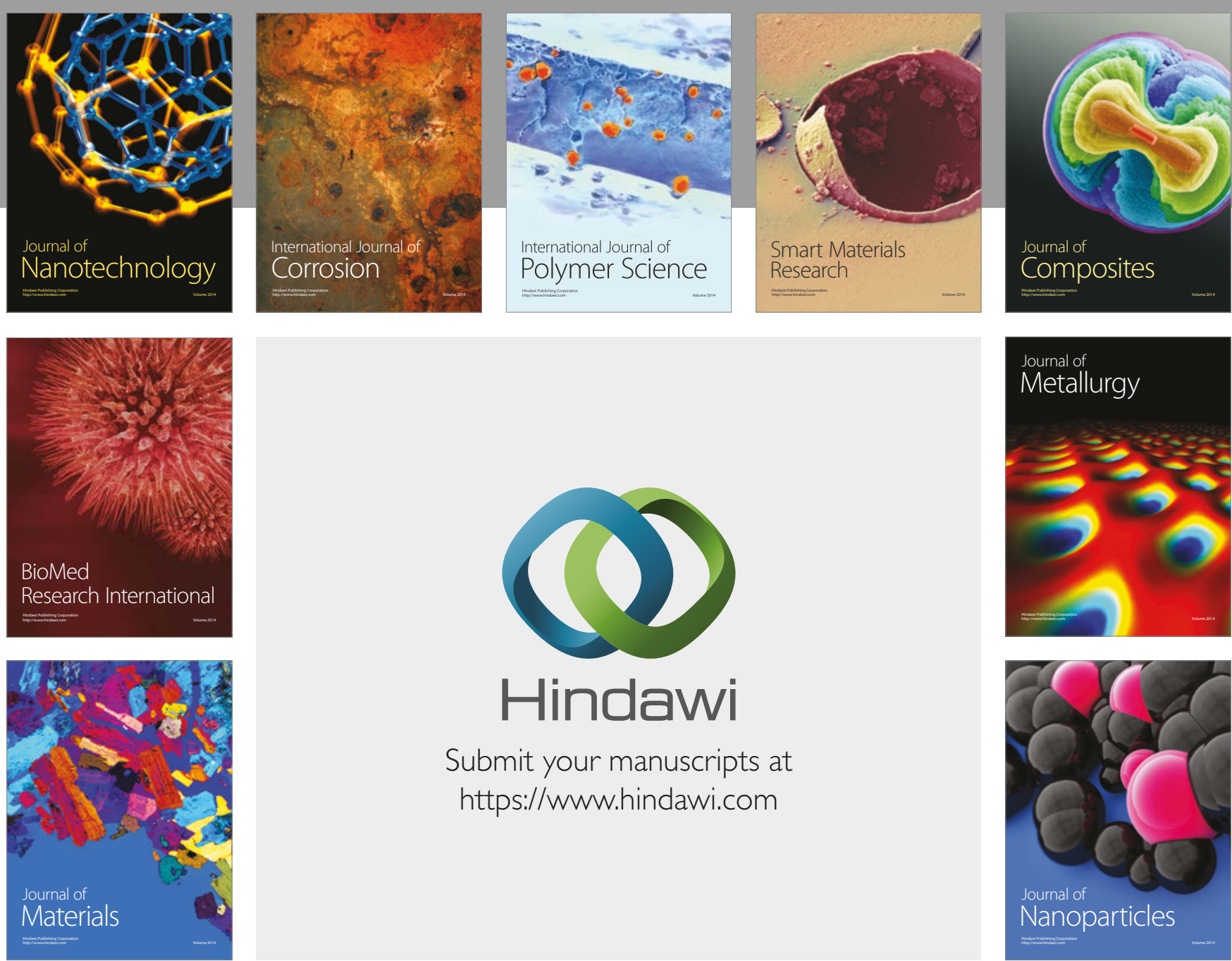

\section{Hindawi}

Submit your manuscripts at

https://www.hindawi.com
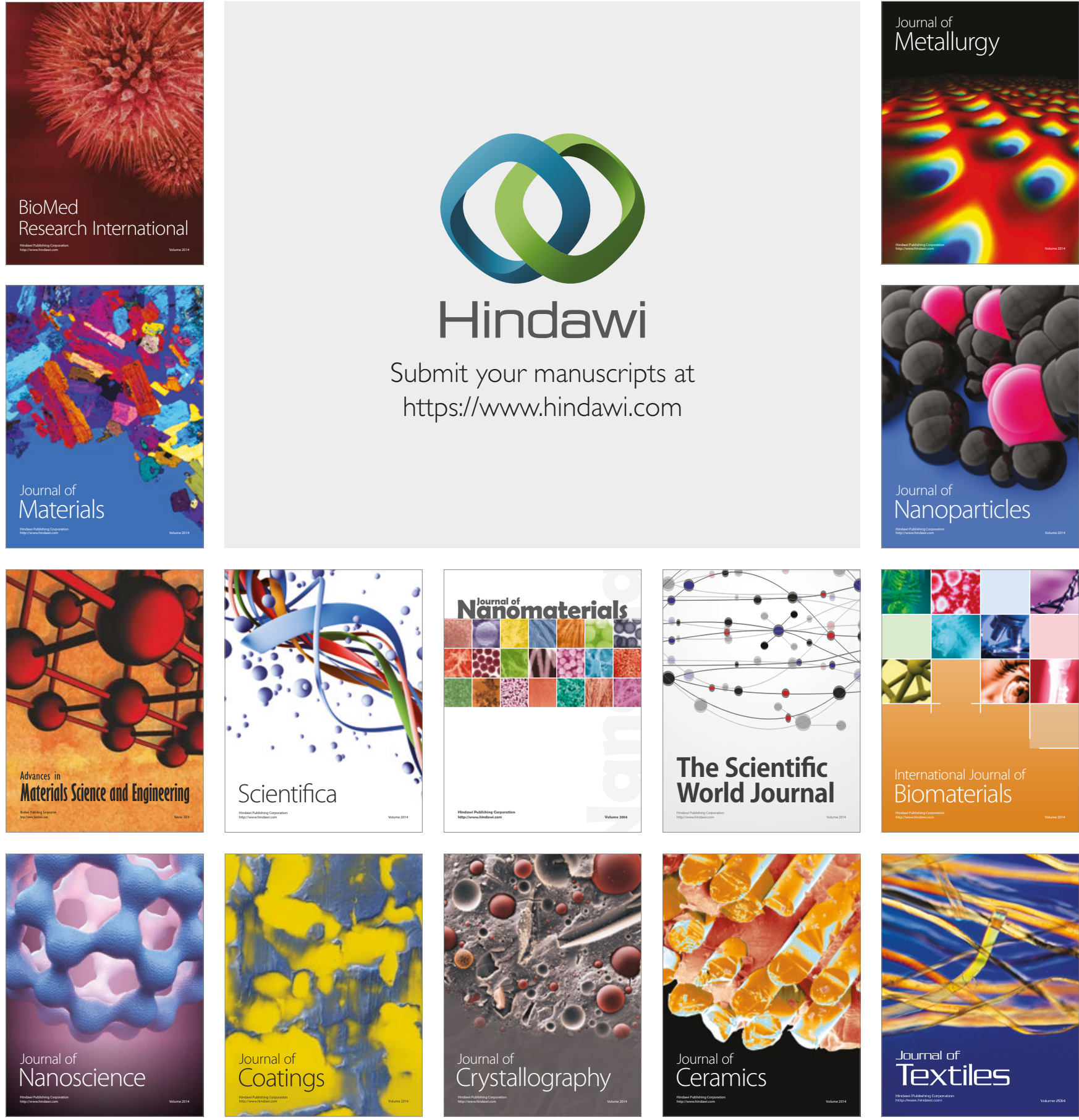

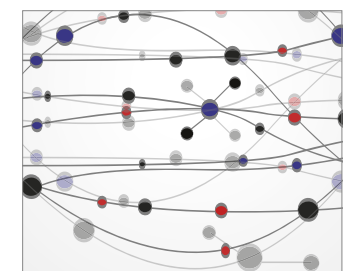

The Scientific World Journal
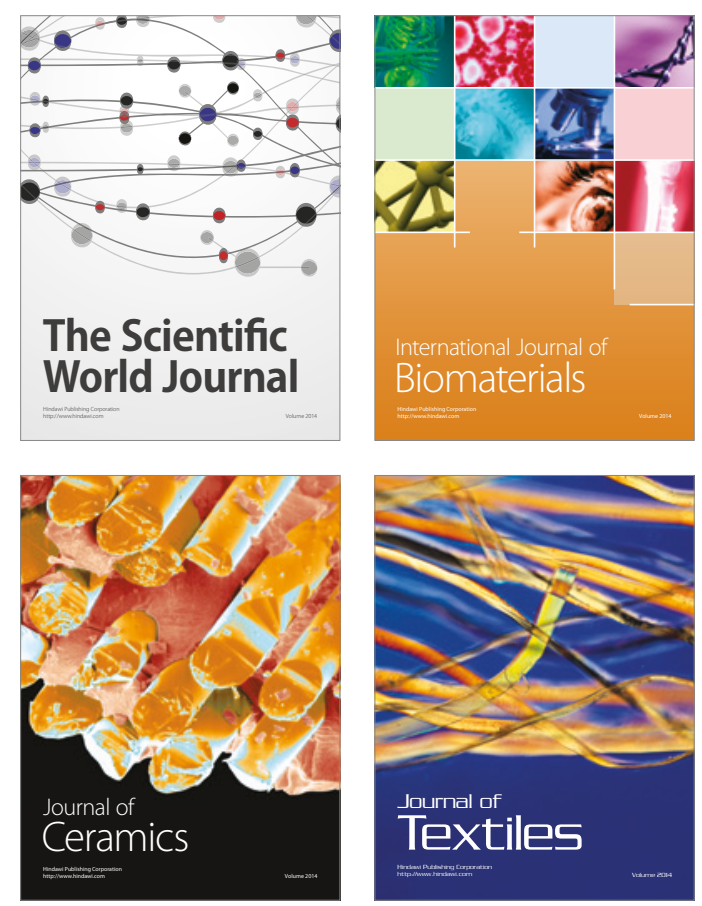